\title{
Correction to: Cognitive dysfunction and subjective symptoms in patients with arachnoid cyst before and after surgery
}

\author{
Louiza Agopian-Dahlenmark $^{1} \cdot$ Tiit Mathiesen $^{2,3,4} \cdot$ Åsa Bergendal $^{4}$ [(]
}

Published online: 29 January 2020

(C) Springer-Verlag GmbH Austria, part of Springer Nature 2020

\section{Correction to: Acta Neurochirurgica}

https://doi.org/10.1007/s00701-020-04225-9

The name of Åsa Bergendal was incorrectly captured in the original manuscript

The correct authorname should be:

$<$ GivenName $>$ Åsa $<$ /GivenName>

$<$ FamilyName $>$ Bergendal $<$ /FamilyName $>$

The original article has been corrected.

The online version of the original article can be found at https://oi.org/ 10.1007/s00701-020-04225-9

\footnotetext{
Tiit Mathiesen

tiit.illimar.mathiesen@regionh.dk

1 Department of Surgery, St Göran Hospital, S:t Göransplan 1, 112

81 Stockholm, Sweden

2 Department of Neurosurgery, Rigshospitalet, Blegdamsvej 9, 2100 Copenhagen, Denmark

3 Institute of Clinical Medicine, University of Copenhagen, 2300 Copenhagen, Denmark

4 Department of Clinical Neuroscience, Karolinska Institutet, 171 76 Stockholm, Sweden
} 